Cadernos de

Pesquisa do CDHIS

DOI 10.14393/cdhis.v34n1.2021.61961

\title{
Tradução
}

\section{Plínio, o jovem, e seu epistolário}

Frederico de Sousa Silva ${ }^{1}$

${ }^{1}$ É professor de Língua e Literatura Latina na Universidade Federal de Uberlândia (UFU). 
Plínio, o jovem, é autor de dez livros de cartas, sendo nove livros de cartas pessoais e um outro de epístolas que trocou com o imperador Trajano. Foram publicadas provavelmente entre 100 e 110 d.C., e englobam período histórico situado nas décadas finais do primeiro século depois de Cristo. Várias informações que temos sobre Plínio, o jovem, ele próprio nos fornece por meio dos dados elencados em suas missivas. Esse autor está situado entre a segunda metade do século primeiro e início do século segundo, e deixou também para a posteridade o Panegírico a Trajano, obra que exalta esse imperador e seus feitos, como deixou, já supracitado, dez livros de cartas. É por meio desse autor, por exemplo, que conhecemos o relato feito ao historiador Tácito a respeito da erupção do Vesúvio em 79 d.C., por meio da carta 20 do sexto livro. De seu epistolário, são 247 cartas selecionadas e dirigidas a 105 destinatários diferentes, escritas do início do principado de Nerva (final de 96 ou começo de 97) até o ano 108 ou 109, muitas vezes agrupadas por temas e não por ordem cronológica. À parte esse número de cartas, há as outras 121 cartas que trocou com Trajano. O próprio Plínio faz referência a essa seleção e organização logo na primeira carta de seu epistolário, enviada a seu amigo Septício:

Caio Plínio saúda seu querido Septício

1 Muitas vezes tu me aconselhaste para que cartas, se algumas com um pouco mais de primor eu tivesse escrito, as reunisse e as publicasse. Reuni-as não observada a ordem de tempo (nem com efeito eu escreveria uma história), mas conforme cada uma delas tenha chegado às mãos. 2 Resta que nem te arrependas de teu conselho nem eu do meu encargo. Desta maneira sem dúvida será feito: que eu busque aquelas que, colocadas à parte até agora, estão no esquecimento e que, caso algumas outras eu escreva, não as guarde. Passa bem.

C. PLINIVS SEPTICIO SVO S.

1 Frequenter hortatus es ut epistulas, si quas paulo curatius scripsissem, colligerem publicaremque. Collegi non seruato temporis ordine (neque enim historiam componebam), sed ut quaeque in manus uenerat. 2 Superest ut nec te consilii nec me paeniteat obsequii. Ita enim 
fiet ut eas quae adhuc neglectae iacent requiram et, si quas addidero, non supprimam. Vale.

Normalmente as cartas têm estrutura fixa, com a apresentação do tema, seu desenvolvimento com pontos de vistas e exemplos, e muitas vezes esse tema servindo como pretexto para apresentação de outras ideias. Ainda sobre o gênero em questão, nos primeiros tratados de retórica gregos que tratam do gênero epistolar, se estabelecem como elementos próprios a brevidade, a simplicidade e a clareza, além da adequação do tom à condição do destinatário, bem como a necessidade de refletir a índole moral do remetente. Mesmo que tenha tido um árduo trabalho de revisá-las e de corrigi-las para publicação, nas cartas de Plínio transparece a espontaneidade, com um refinamento que vai da simplicidade à elegância, demonstrando de forma clara as influências recebidas de Cícero e de Sêneca.

A sociedade de Plínio constitui o centro de sua escrita e daí suas cartas se transformam em uma rica fonte de notícias sobre a vida romana da época de Nerva e de Trajano. Nas suas missivas há uma impressão, muitas vezes, de que ele se utiliza da temática proposta na carta enviada para poder apresentar outra temática, apresentando ao leitor outras ideias. Algumas vezes, também, Plínio utiliza-se do outro, da temática que se liga a outro, para que possa escrever sobre si mesmo, fazendo com que ele próprio seja modelo e que fique registrada para a posteridade sua marca. Dessa maneira, por meio das cartas, consegue-se vislumbrar um pouco do que poderíamos constatar como uma vida cotidiana, um pouco das engrenagens sociais da época de Plínio. Já no campo político, Plínio é partidário das ideias de Trajano, mas em algumas cartas deixa transparecer certa saudade de um passado republicano.

Constituem parte de seus temas a vida social, como referência a amigos, descrições de obituários, como aspectos a respeito das leituras públicas literárias (tema sobre o qual há grande número de cartas), a vida privada, como 
cartas acerca da família, dos libertos, sobre o amor à literatura, cartas para a esposa; enfim, deixou para a posteridade grande diversidade de temas e conteúdos. Para este presente texto, propõe-se dar uma amostra desse rol de correspondências a presentado tradução da carta 14 do livro III, em que se dirige a Acílio, carta provavelmente situada entre 105 e 110.

\section{Caio Plínio a seu querido Acílio}

1 Ataque atroz, digno não somente de uma carta, sofreu de seus próprios servos Lárcio Macedo, homem de linhagem pretoriana; era, por outro lado, senhor arrogante e cruel e que pouco se lembrava de que seu próprio pai havia sido escravo ou, pelo contrário, lembrava-se muito. 2 Lavava-se na vila Formiana e de repente os servos o rodeiam. Um se atira contra sua garganta, outro esmurra seu rosto, outro golpeia seu peito e estômago e também, repugnante de dizer, suas partes íntimas. E como o julgassem sem vida, lançamno em chão ardente, para que comprovassem se acaso vivia. Ele, ou porque não sentia nada, ou porque fingia não sentir, imóvel e estendido atestou a impressão da morte certa. 3 Somente então é retirado dali, por assim dizer debilitado devido ao grande calor; acolhem-no os servos mais fiéis, as concubinas com gritos e lamentações correm para lá. Assim, estimulado pelas vozes e reanimado pelo frescor do lugar, entreabrindo os olhos e movimentando o corpo, mostra que vivia, e agora estava também em segurança. 4 Os escravos fogem. Grande parte deles foi presa, os outros ainda são procurados. O próprio Macedo, reanimado com dificuldade, morreu poucos dias depois não sem a compensação da vingança. Assim, como costumam serem vingados os assassinados, ele o foi em vida. 5 Vês tu a quantos perigos, a quantas afrontas, a quantos ultrajes estamos expostos; nem há o fato de que alguém possa estar em segurança porque seja menos rigoroso e gentil. Com efeito, os senhores são assassinados não por algum discernimento dos servos, mas devido a uma 
intenção criminosa. Mas estas informações são o bastante. $6 \mathrm{O}$ que há de novo, além disso? O quê? Nada; de qualquer modo mais acrescentaria, pois ainda me sobra papel e o dia festivo permite escrever muito mais. Acrescentarei aquilo que oportunamente, a respeito desse mesmo Macedo, vem à memória. No momento em que se lavava em um banho público de Roma, aconteceu uma situação notável e também, como o resultado mostrou, de mau agouro. 7 Um cavaleiro romano, advertido levemente com a mão por um escravo de Macedo para que abrisse caminho, voltou-se e golpeou de forma tão intensa com a palma da mão não o escravo, pelo qual havia sido tocado, mas o próprio Macedo, que quase o matou. 8 Assim, o banho para ele, por assim dizer, por meio de certa gradação, foi o local primeiramente de afronta, em seguida o de sua morte. Passa bem.

\section{PLINIVS ACILIO SVOS.}

1 Rem atrocem nec tantum epistula dignam Larcius Macedo, uir praetorius, a servis suis passus est, superbus alioqui dominus et saeuus et qui seruisse patrem suum parum, immo nimium meminisset. 2 Lauabatur in uilla Formiana; repente eum serui circumsistunt, alius fauces inuadit, alius os uerberat, alius pectus et uentrem atque etiam, foedum dictu, uerenda contundit; et, cum exanimem putarent, abiciunt in feruens pauimentum, ut experirentur an uiueret. Ille, siue quia non sentiebat, siue quia non sentire se simulabat, immobilis et extentus fidem peractae mortis impleuit. 3 Tum demum quasi aestu solutus effertur; excipiunt serui fideliores, concubinae cum ululatu et clamore concurrunt. Ita et uocibus excitatus et recreatus loci frigore sublatis oculis agitatoque corpore uiuere se, et iam tutum erat, confitetur. 4 Diffugiunt serui; quorum magna pars comprehensa est, ceteri requiruntur; ipse paucis diebus aegre focilatus non sine ultionis solacio decessit, ita uiuus uindicatus, ut occisi solent. 5 Vides quot periculis, quot contumeliis, quot ludibriis simus obnoxii; nec est quod quisquam possit esse securus, quia sit remissus et mitis; non enim iudicio domini, sed scelere 
perimuntur. Verum haec hactenus. 6 Quid praeterea noui? quid? nihil; alioqui subiungerem, nam et charta adhuc superest, et dies feriatus patitur plura contexi. Addam quod opportune de eodem Macedone succurrit. Cum in publico Romae lauaretur, notabilis atque etiam, ut exitus docuit, ominosa res accidit. 7 Eques Romanus a seruo eius ut transitum daret manu leuiter admonitus conuertit se nec seruum, a quo erat tactus, sed ipsum Macedonem tam grauiter palma percussit, ut paene concideret. 8 Ita balineum illi quasi per gradus quosdam primum contumeliae locus, deinde exitii fuit. Vale.

Esta carta estrutura-se na forma de narrativa de um episódio acontecido em Roma. Plínio, na tessitura da carta, não deixa de priorizar aspectos retóricos para a construção de sentido. A lítotes, por exemplo, figura que sugere uma ideia pela negação do seu oposto, se faz presente no início da missiva em nec tantum epistula dignam (digno não somente de uma carta), expressando assim que o fato é merecedor de mais de uma carta. No mesmo período, Plínio articula uma aliteração em a servis suis passus est (sofreu de seus próprios servos), efeito que conseguimos manter na tradução para o português. Outros recursos inseridos pelo autor estão na repetição polissindética em siue quia non sentiebat, siue quia non sentire se simulabat (ou porque não sentia nada, ou porque fingia não sentir) e na anafórica em quot periculis, quot contumeliis, quot ludibriis simus obnoxii (a quantos perigos, a quantas afrontas, a quantos ultrajes estamos expostos) e em Quid praeterea noui? quid? (O que há de novo, além disso? $\mathrm{O}$ quê?).

Há outros recursos no texto de que Plínio lança mão para construir sua narração, e um ponto importante a destacar é o uso de verbos no presente, como em circumsistunt, inuadit, uerberat, contundit (e de repente os servos o

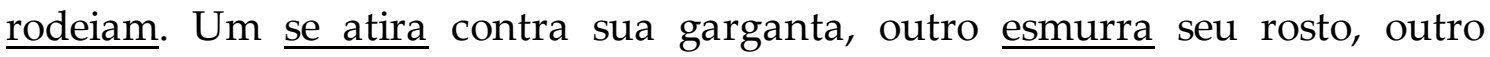
golpeia seu peito e estômago e também, repugnante de dizer, suas partes íntimas). $\mathrm{O}$ autor torna a ação simultânea à leitura do destinatário, o que faz 
com a cena torne-se mais contundente. Além disso, nessa tessitura, ao focalizar os atos dos escravos, utiliza-se de orações curtas com o objetivo de representar a rapidez do ataque, e o faz com orações justapostas, não subordinadas. Tudo isso gera um efeito bem mais dramático à cena narrada com as ações pontuais. Entre as várias estratégias utilizadas, destaco ainda, ao final da carta, a fina ironia que faz em relação aos banhos públicos, em Ita balineum illi quasi per gradus quosdam primum contumeliae locus, deinde exitii fuit (Assim, o banho para ele, por assim dizer, por meio de certa gradação, foi o local primeiramente de afronta, em seguida o de sua morte).

Dessa forma, então, apresenta-se nesta tradução proposta pequena amostra do arcabouço deixado por Plínio, cartas ainda inéditas em língua portuguesa que são objeto de nossa pesquisa, em andamento, de pósdoutorado. De inegável importância, o epistolário de Plínio aborda, como já citado, as mais variadas temáticas, com estilo que vai da simplicidade à elegância.

\section{REFERÊNCIAS BIBLIOGRÁFICAS}

ALFÖDY, Géza. A História Social de Roma. Lisboa: Editorial Presença. 1989.

ARISTÓTELES. Retórica. Tradução e notas de Edson Bini. São Paulo: Edipro, 2013.

FUNARI, Pedro Paulo. Grécia e Roma: vida pública e vida privada. São Paulo: Editora Contexto, 2015.

GIARDINA, Andréa. O Homem Romano. Lisboa: Editorial Presença, 1992.

LAUSBERG, Heinrich. Elementos de Retórica Literária. Lisboa: Fundação Calouste Gunbenkian, 1972. 
PLINE LE JEUNE. Lettres (livre X): Panégyrique de Trajan: vol. IV. Texte établi et traduit par Marcel Durry. Paris: Les Belles Lettres, 1964. 200 p.

Lettres (livres I-III): vol. I. Texte établi et traduit par AnneMarie Guillemin. Paris: Les Belles Lettres, 1961. 146 p.

Lettres (livres IV-VI): vol. II. Texte établi et traduit par Anne-Marie Guillemin. Paris: Les Belles Lettres, 1961.146 p.

Lettres (livres VII-IX): vol. III. Texte établi et traduit par Anne-Marie Guillemin. Paris: Les Belles Lettres, 1928. 193 p.

QUINTILIANO. Instituição Oratória: Tomos I, II, III, IV. Trad. Bruno Bassetto. Campinas: Editora Unicamp, 2015.

RICOUER, Paul. Sobre a tradução. Belo Horizonte: Editora UFMG, 2011. 